\title{
Tiempo trágico: estructura anular y esquemas mistéricos en los cantos corales de Antígona de Sófocles (parte i)
}

\section{SANTIAGO HERNÁNDEZ APARICIO \\ Universidad Nacional de Rosario / CONICET santiago.hernandezaparicio@yahoo.com.ar}

En el presente artículo nos proponemos reconocer y analizar el uso de la técnica de la ring-composition o estructura anular en los cantos corales de Antígona de Sófocles en relación con los elementos de los cultos eleusino y dionisíaco que atraviesan la obra. Nuestra hipótesis consiste en que, lejos de ser un factor de mera articulación formal, la ring-composition cumple con una función dramática pues cohesiona, con su juego de paralelismos, las alusiones a los misterios con el fin de presentar la acción como un ritual iniciático fallido. En esta primera parte trataremos el marco general de análisis y el canto de entrada del coro.

Ring-composition / Canto coral / Antígona / Misterios eleusinos / Misterios dionisíacos

TRAGIC TIME: RING COMPOSITION AND MYSTERY CULTS IN THE CHORAL SONGS OF SOPHOCLES' ANTIGONE

In this article we aim to recognize ring-composition and to analyze how it is used in Sophocles' Antigone's choral songs in connection with the elements from the Eleusinian and the Dionysian cults that pervade the play. Our hypothesis claims that, rather than being a mere factor of formal articulation, ring-composition has a dramatic function because it articulates the allusions to the mysteries through an interplay of parallelisms in order to represent the action as a failed initiation ritual. In the first part we develop our theoretical framework and analyze the chorus entry song.

Ring-composition / Choral song / Antigone / Eleusinian mysteries / Dionysian mysteries 


\section{Introducción}

La codificación de elementos del culto eleusino en Antígona de Sófocles (443-438 a. C.) se articula mediante una superposición poética en la hija de Edipo: su equiparación metafórica con la figura materna de Deméter y, como lo ha advertido Charles SEgAL (1999: 179-183), con la de Perséfone, la doncella que viaja al submundo. Por otro lado, es posible advertir elementos del culto dionisíaco (representación de Antígona como bacante y de Creonte como $\theta \varepsilon o ́ \mu \alpha \chi o \varsigma$, la presencia relevante del lamento) que, si seguimos la hipótesis de Richard SEAFORD (1981: 2012), podrían deberse a dos motivos: el origen de la tragedia en los misterios dionisíacos y su $\alpha$ í̃ ıov narrativo de la resistencia al culto del dios que $\operatorname{llega}^{1} \mathrm{y}$, como consecuencia de ello, el patrón común a todas las tragedias de hundimiento de la casa real e instauración de un culto de la pólis que apunta hacia la cohesión comunitaria. La fusión de ambos misterios en un subtexto o patrón mítico común no resulta descabellada ya que, además de compartir características formales y la figura de Dioniso (el Yaco de la procesión del 19 de boedromión), implican la llegada de una divinidad desde lejos, que asume el control del eje cósmico del espacio y lo delega a la pólis, que lo ejercitará miméticamente en el rito mistérico (SEAFORD 2012: 100). Este modelo explicativo, sin embargo, encuentra interferencias en Antígona, en especial porque el drama no culmina con la fundación de un culto o rito que beneficie a la ciudad. ¿Entonces cómo entender los elementos mistéricos? Seguiremos a SEAFORD (2012) en su definición de tragedia como cronotopos en pugna, pero resaltaremos la peculiaridad de la presentación sofoclea del conflicto. Efectivamente, los cronotopos que luchan en esta tragedia no se resolverían en una síntesis sino que, mediante la violencia intrafamiliar y la perversión ritual propia del género, intensificarían la crisis hasta su destrucción mutua. El coro, como bisagra entre mito y ritual, no interpretaría el proceso trágico como un viraje desde lo indeterminado hacia lo determinado, sino que subvertiría los esquemas míticos de iniciación mistérica (dionisíaca y eleusina) para presentar la acción como un rito iniciático fallido. Lo lograría a merced de la técnica de la ring-composition o composición anular, símbolo de un ciclo alterado, un tiempo trágico.

\section{El tiempo en la tragedia y los cronotopos de Antígona}

Afirma Hermann FRÄNKEL en su pionero estudio sobre el tiempo en la poesía arcaica ([1931]1955: 13):

Für die archaische Auffasung war die Zeit in den begegnenden Dingen wirksam: sie war die Kraft die Alles heranführt, der Wind gleichsam der uns die Begebnisse zuweht. Deshalb war sie immer, wie Pindar sie gern nennt, kommend, war sie spätere Zeit und Zukunft. Jetzt aber, im klassischer Auffasung, ist Zeit auch bei uns, den Erlebenden; sie ist auch in unserem 
Schreiten, wenn wir den Begebnissen entgegengehen und durch sie hindurchgehen².

Según el estudioso, a partir de la Orestíada de Esquilo la noción griega de

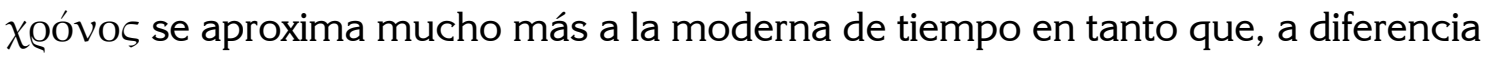
de la poesía arcaica, que lo concebía como un aspecto negativo o positivo de los eventos, la literatura clásica lo introyecta en la subjetividad, al modo de una categoría apriorística de la percepción en el sentido kantiano ("in den Begebnissen wirksamen Kräfte werden nicht mehr an den Dingen wahrgenommen sondern in den Erlebenden hineingezogen”3). Lo que FRÄNKEL leía, desde su postura evolutiva, como una idea poco clara del tiempo en Homero y los líricos, sin duda se correspondía con una construcción social distinta de esta categoría cultural. Sin embargo, su afirmación de un cambio importante en la concepción del tiempo en el drama del siglo $\mathrm{V}$, abastecida por un minucioso análisis léxico, es correcta. Jacqueline de RoMILLY (1968) retoma su línea para profundizar en la tragedia. A partir de la definición aristotélica del género como mímesis de acciones serias y completas ${ }^{4}$, interpreta su contenido como el de una crisis que subvierte todo lo que había existido antes y, por lo tanto, manifiesta una conciencia aguda del tiempo en dos sentidos: en primer lugar, la tragedia delimita una secuencia temporal ${ }^{5}$ en la que se sigue una acción de principio a fin, sin mediación narrativa ${ }^{6} \mathrm{y}$, por lo tanto, minuto a minuto como si se tratase del presente; por el otro lado, este evento definitorio es serio, ya que condensa el pasado y el futuro al ser crítico en sentido etimológico - KQíveı v como juzgar o decidir- (6-9).

Esta postura ha sido criticada desde cierto escepticismo empirista por estudiosos como MOMigliano (1966) o LlOYD- JONES (1970) que sostienen que no es posible hacer inferencias sobre la peculiaridad de la experiencia del tiempo de una cultura lejana a partir de la exploración de su figuración a través de convenciones literarias. Sin embargo, si consideramos al tiempo como un constructo cultural no nos resulta tan lejana la idea de que su experiencia pudiera moldearse a través de los mismos procesos en la "realidad" y en los textos, más aun teniendo en cuenta que la "literatura" griega no contaba con la autonomía de la institución artística moderna?. Por este motivo nos resulta sumamente productiva la lectura de SEAFORD (2012) de la tragedia como cronotopos en pugna ${ }^{8}$. A partir de los desarrollos de Mijaíl BAJTín (1989), arriba a una noción de cronotopo que supera lo estrictamente literario; se trata de estructuras cognitivas bajo la forma de marcos espacio-temporales homogéneos, funcionales en la mente pero construidos socialmente, en relación con instituciones o prácticas de integración social (2012: 1-5). En la Grecia antigua, estas instituciones sobre todo consistieron en las prácticas de reciprocidad, tal como aparecen en la aristocracia homérica; en el pago con dinero y en los ritualles de la pólis. Si bien las unidades de espacio y tiempo construidas a partir de estas prácticas eran sociales, se vivían como trascendent[ales]es (quizás también en el sentido kantiano antes advertido en FRÄNKEL $^{9}$ ), ya que atravesaban un proceso de "cosmisation" (3) explicable no solo como legitimación de las relaciones de poder, 
sino como comprensión de lo desconocido (el cosmos) a partir de lo conocido (las relaciones sociales).

Así, como describe SEAFORD, el cronotopo recíproco imagina al espacio-tiempo en términos de relaciones entre dos unidades irreductiblemente distintas, como los partidos aristocráticos que se dispensaban daño o beneficio a partir del principio de retribución. El cronotopo monetizado, por su parte, imagina el espacio-tiempo a través de la reducción de opuestos a unidad y la disolución de límites internos en aras de una homogeneización abstracta, como el dinero que no solamente era intercambiable por cualquier cosa, sino que, para funcionar, mantenía su valor (de cambio) en el espacio y en el tiempo. A contracara de estos cronotopos que no necesitan conectarse con un tiempo-espacio singular, el cronotopo etiológico del rito "defines a particular space and particular time so as to transform a series of individuals in a cohesive group" (2012: 5). Esta definición es justificada por un alı́t cronotopo etiológico implica un movimiento desde lo indefinido (el estado de cosas caótico del mito etiológico) hacia lo definido (el culto fundado) que puede ser representado por dos sub-cronotopos: el indeterminado, con su disolución de límites; y el determinado, conclusión desde la que se mira hacia el pasado mítico. Por ello este tiempo-espacio es lineal -un pasaje- pero también cíclico, pues revive periódicamente un mito que acerca y hasta une lo remoto y lo actual. La tragedia, como ritual cívico en las Dionisias Ciudadanas, adquiría la forma de un cronotopo etiológico, sobre todo si la pensamos como condicionada por la matriz dinámica del mito dionisíaco, pero a la vez subsumía otros cronotopos. Desplegaba, con el establecimiento del culto final, un cronotopo determinado, pero también uno indeterminado visible en las perversiones rituales de la trama, ubicada en espacios y tiempos salvajes. Podría hablarse de una lucha de cronotopos: el de la casa aristocrática o real derrocada y el del dios comunal de la pólis. Pero SEAFORD no incluye en la lucha a los tres cronotopos sino que desarrolla un modelo evolutivo: efectivamente, en el siglo VI, el cronotopo recíproco fue reemplazado por el monetizado a medida que la sociedad hoplítica iba perdiendo sus privilegios ${ }^{10}$. Con el advenimiento de la tiranía, que resalta el aspecto negativo de la institución monetaria, la crisis etiológica de alguna manera funde en el cronotopo indeterminado a la casa real con el tirano, al cronotopo recíproco con el monetizado ${ }^{11}$, y ambos son superados por el cronotopo determinado final. Así encontramos, en diversas tragedias, a reyes con atributos tiránicos ${ }^{12}$, cuya caída es el triunfo de la pólis. Por ejemplo, Eteocles en Siete contra Tebas o Penteo en Bacantes.

Este modelo no funciona en Antígona porque no explica su estructura en díptico, el sentido de los dos destinos trágicos. Creonte efectivamente aparece con todos los atributos propios del tirano: perversión del ritual, acumulación monetaria y asesinato de parientes (SEAFORD 2012: 67), pero Antígona no. Pero esto claramente no quiere decir que Antígona encarne algún valor político que triunfe con la caída de la tiranía. Parece caracterizarla más bien la endogamia propia de las tradicionales familias aristocráticas, y su comportamiento es aquileo. Al mismo tiempo, 
la caracterización tiránica de Creonte impide considerar, como lo han hecho HEGEL y sus epígonos, una Aufhebung (superación) de la ley de la familia por la ley estatal que sobrevuela la obra como Versöhnung (conciliación) sintética (1908 [1842]; 2000 [1821]). El problema es, justamente, leer Antígona desde la perspectiva de la síntesis ${ }^{13}$. Proponemos hacerlo como una dialéctica sin síntesis entre dos cronotopos que luchan: el cronotopo recíproco del oîkos de Antígona y el cronotopo monetizado de la pólis de Creonte. A modo de subversión del esquema mistérico, como crisis etiológica no resuelta, el Dioniso del éxodo oscila entre presencia invisible que destruye Tebas o ausencia visible que la deja librada al suicidio por sus conflictos intestinos.

Las ambigüedades de la tragedia de alguna manera se intensifican desde esta perspectiva: el cronotopo monetizado del tirano Creonte aparece paradójicamente ligado a la pólis ${ }^{14}$ y el cronotopo recíproco de Antígona, propio de una realeza habitualmente representada como tiránica, se resiste a la homogeneización monetaria. Esto puede observarse si evaluamos brevemente el uso de las metáforas monetarias en ambos personajes. Para Creonte, el poder de la moneda extendido al universo ético permite que valores plurales e inconmensurables pasen a ser arreglados según una escala de valores menores y mayores -el régimen de evaluación comparativa del comercio-, donde uno, hipostasiado en la punta de la pirámide, actúa como

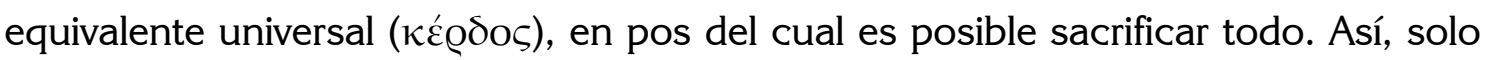

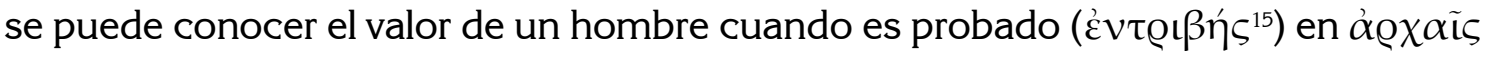

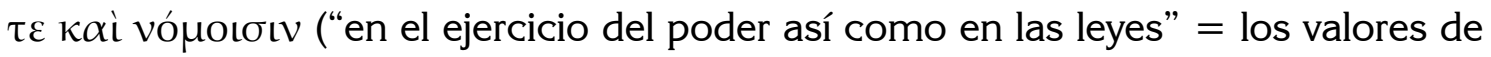
la pólis). Creonte se olvida de su lugar de cabeza de un oîkos para actuar como un gobernante puro, sin división ni conflicto entre distintos intereses. La apropiación egoísta de un significante universal revela una hýbris tiránica, e históricamente tiranos como Pisístrato e Hipias (SEAFORD 1998, 136) controlaron la acuñación de la moneda como un método para conservar el poder. El edicto sobre Polinices, como una ley "para todos", pero que hipostasía los valores de algunos, sin duda tiene este sello. No obstante, una metáfora empleada inmediatamente después de la comunicación del edicto alude a un contenido sociopolítico distinto. El coro, en relación con la amenaza del castigo, comenta a Creonte (vv. 221- 223):

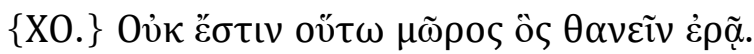

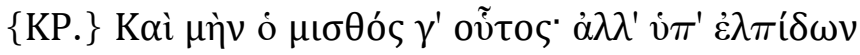

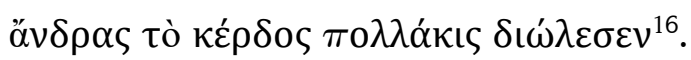

Coro. - No hay nadie tan tonto que desee morir.

Creonte. - En verdad esa será la paga. Muchas veces, con esperanzas de ganancia los hombres se destruyen.

La misthophoría es una institución fuertemente entrelazada con el sistema democrático. Aseguraba un salario (misthós) por servicios ciudadanos en las funciones públicas, tales como la marina, la asamblea, los tribunales judiciales y hasta las festividades cívicas como el teatro. Ahora, que la muerte sea $\mu$ ı $\theta$ ó 
que un sarcasmo en boca de Creonte, pero para Antígona es una realidad incontrovertible. De todas las actividades cívicas que la pólis retribuye económicamente, enterrar a un traidor a la patria no cuenta, porque lo que no se valora no se paga.

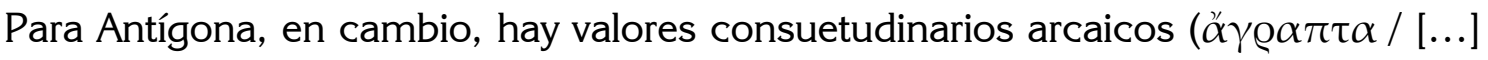
vó $\mu \iota \mu \alpha$, vv. 454-455) que no son negociables en tanto, siendo inconmensurables, no caben en una escala de valores monolítica. Las referencias a lo fúnebre como

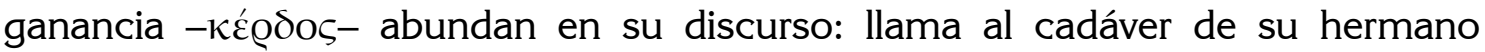

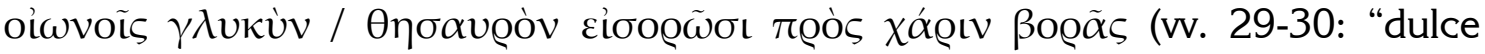
tesoro para las aves de rapiña, que lo miran desde arriba con el placer de la

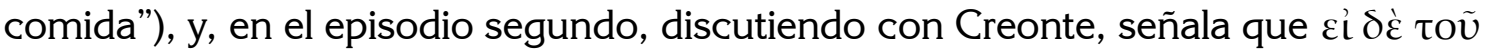

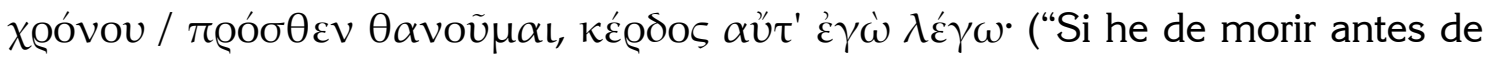
tiempo, confirmo la ganancia", vv. 461-462). El término sustituyente monetario tiene en Antígona y Creonte un término sustituido diametralmente opuesto (los valores del oîkos, en un caso, los de la pólis, en otro), dado que el tertium comparationis, la virtud de ser un equivalente universal, encuentra caminos diferentes en la textura ideológica de cada personaje. Existe una dificultad, sin embargo, en la aplicación de kérdos como sustituyente de "muerte", dado que toda ganancia implica un excedente, pero la muerte, como experiencia total y fulminante, no es fragmentable, nada la excede. Honrar a los muertos de la familia puede, sin duda, circular en el mercado de valores éticos con miras a su reconocimiento, incluso, como equivalente universal, pero morir es salir de circulación, y quizás sea el com-

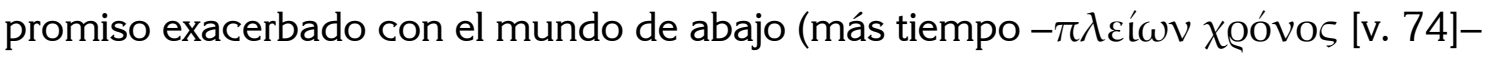
perma-necerá ahî) lo que coloque a Antígona en un lugar tan cuestionable como el de Creonte. Su deseo de unión (cincestuosa?) con el muerto es demasiado grande como para permanecer entre los vivos, como si la perspectiva de la eternidad la convirtiera en un cadáver viviente pues, amando la casa, paradójicamente, quiere casarse con Hades.

Se podría pensar, entonces, en la representación cronotópica de conflictos entre la sociedad tradicional ática y los nuevos aspectos surgidos en ella ${ }^{17}$. Los héroes intransigentes tensionan hasta el límite su postura y son incapaces de reconocer en sí mismos aspectos de la postura del otro: lo que podría haber sido un quiasmo integrativo acaba en antítesis destructiva ${ }^{18}$. El cronotopo monetizado de cierta forma encarna el ideal pericleano de la ciudad-isla, expresado en el discurso fúnebre a los caídos el primer año de la guerra (Th. 1.34-35). La pólis se imagina como una nave; sin tierra cultivable, se limita al mar, ámbito de las actividades económicas que se desarrollaron con el uso del dinero: el comercio con tierras lejanas y el cobro de tributos. Olvida, en su origen, el papel de los oîkoi que se fusionaron en unidad agraria durante el synoikismós mítico de Teseo ${ }^{19}$. El cronotopo recíproco también se aísla, bajo la figura del útero o de la cueva, y rechaza lo político con su ímpetu endogámico. La homogeneización incestuosa de los Labdácidas se opone a la homogeneización abstracta de los ciudadanos de las reformas clisténicas, que buscaban aliviar la fidelidad al génos para intensificar la lealtad a la pólis. El tiempo 
de Antígona es breve y urgido porque pertenece a los muertos; el tiempo de Creonte es ilimitado porque no tiene fisuras ${ }^{20}$.

\section{La estructura anular como técnica dramática}

Ring-composition o estructura anular es el nombre de una técnica compositiva donde fondo y forma resultan las dos caras de una misma moneda. En la literatura occidental, su uso puede rastrearse desde los poemas homéricos, pero disminuye drásticamente en la modernidad, con la exaltación de un tiempo ya teleológico, ya lineal. Sin embargo, su presencia en la Antigüedad no tenía que coincidir necesariamente con una noción cíclica del tiempo y menos aún con un modelo cerrado y/o simplista del mundo, como podemos vernos tentados a pensar. Es en este sentido que nos interesa en Antígona.

Mary DOUGLAS define esta técnica como "a construction of parallelisms that must open a theme, develop it and round it off by bringing the construction back to the beginning" (2007: 10). Para este trabajo con la unidad sugerido por la forma del anillo, es esencial la presencia marcada de un punto de retorno (turning-point) en el medio de la estructura, a partir del cual las secciones de su segunda parte realicen una cuenta regresiva tanto formal como temática hasta retomar el principio. Cada sección de la primera mitad tiene una sección paralela antitética o sinónima en la segunda mitad. En la tragedia, la correlación entre secciones puede realizarse a través de una amplitud variada de tipos de unidades: bien puede darse estrictamente entre escenas o entre episodios ${ }^{21}$, entre cantos corales, o bien, como afirma Esteban SANTOS (1996: 10-12), puede articularse una estructura más laxa, donde un episodio o estásimo ocupa el lugar de turning-point ${ }^{22}$ y alrededor suyo se agrupan tanto episodios como escenas o cantos corales. Desde el punto de vista estrictamente episódico, el centro de Antígona es el episodio III (vv. 626-780), y es ahí donde se ubica, como gnóme en boca de Creonte, el verso central de la obra en términos

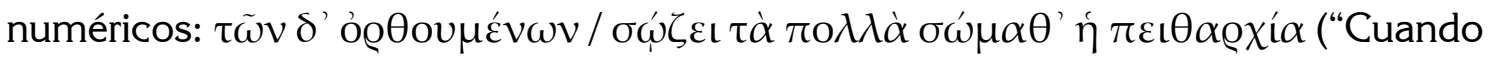
la conducción es recta, la obediencia salva a la mayoría”, vv. 675-676). El verso evoca inmediatamente a la nave del estado ${ }^{23}$ nadando sobre las peligrosas aguas del génos, metáfora del conflicto de la obra, y a la vez resulta irónica pues la obediencia al monarca resulta un holocausto para, por lo menos, lo que resta de la casa de Edipo y la de Creonte.

Sin embargo, privilegiamos la estructura anular que se puede leer en los cantos corales no solo por una obvia cuestión de espacio, sino porque presentan una especial comprensión del proceso trágico como conflicto en términos de subversión ritual, pero a su vez sintetizan la dimensión política que aparece con mayor evidencia en los diálogos. El grupo de quince coreutas que media en la orquestra entre los personajes y el público, bailando, cantando y dialogando con los actores, de alguna manera interrumpe el tiempo urgido de la acción de los personajes, y su canto sobre la naturaleza de la acción humana le otorga al tiempo-espacio de la obra un largo alcance $^{24}$. Si HeGEL, como explica Joshua BILlings (2013: 332-3), coloca al coro en 
una etapa primitiva de la evolución del espíritu -su teología pluralista le impediría comprender que las divinidades del panteón son las manifestaciones de una sustancia ética única- nosotros lo entendemos como la instancia donde se consolida el sentido de la tragedia, pues comprende al conflicto como la verdad de la sustancia ${ }^{25}$. Con esto apuntamos a que, si bien la dimensión cultual de la representación trágica en Atenas da preeminencia al espacio ritual como medio de cohesión social, los coros de Antígona ponen el acento en el hundimiento de las instituciones que cohesionarían Tebas y por lo tanto colocan al tempus destruendi como dimensión preeminente.

Primero expondremos en detalle los paralelismos de la párodos para demostrar que la estructura anular no solo se da entre cantos, sino dentro de ellos. Luego nos dedicaremos a los stasima centrales, para resaltar los paralelismos entre cantos y articular con mayor claridad la cuestión de la subversión de los esquemas míticos mistéricos. Finalmente, exploraremos en el estásimo $\mathrm{V}$ tanto sus paralelismos internos como su relación con la párodos, que permite leer una conexión entre la metateatralidad y el sentido final del anillo.

\subsection{Párodos, vv. 100-154 (sin estrofa anapéstica final)}

La párodos, que podría considerarse un himno de agradecimiento a los dioses que salvaron Tebas (GRIFFITH 1999: 139), es cantada por el coro de quince ancianos tebanos en representación de toda la ciudad (v. 102), antes de que se los asocie con

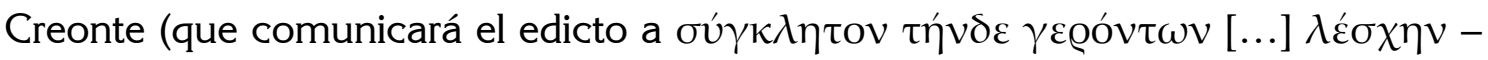
"la asamblea convocada de los ancianos"-, vv. 160-161). A contracara del prólogo, presenta el estado de la situación, pero de modo luminoso y desde el punto de vista de Tebas. La componen dos estrofas y dos antístrofas donde predominan los metros eólicos, con una tendencia glicónica en las primeras y coriámbica en las últimas. Cada estrofa y antistrofa, sin embargo, está compuesta por dos estrofas en sentido moderno, por lo que hay un total de ocho estrofas, del que es preciso descontar los anapestos finales ${ }^{26}$, que quedan fuera de la estructura anular, asegurando la independencia de la oda. Estos siete elementos presentan una ring-composition A-B-CD-C'-B'-A', donde C y C' están en anapestos.

\begin{tabular}{|c|c|c|c|}
\hline $\begin{array}{l}\text { A } \\
\text { vv. 100-109 }\end{array}$ & $\begin{array}{l}\text { Himno } \\
\text { (os) }\end{array}$ & (metros eóli- & $\begin{array}{l}A^{\prime} \\
\text { vv. 148-155 }\end{array}$ \\
\hline $\begin{array}{l}\text { B } \\
\text { vv. 110-111 }\end{array}$ & \multicolumn{2}{|c|}{ Amigos y enemigos (anapestos) } & $\begin{array}{l}B^{\prime} \\
\text { vv. 141-147 }\end{array}$ \\
\hline $\begin{array}{l}\text { C } \\
\text { vv. 117-126 }\end{array}$ & Dioses en la guerra & (metros eólicos) & $\begin{array}{l}C^{\prime} \\
\text { vv. } 134-140\end{array}$ \\
\hline & $\begin{array}{l}\text { D } \\
127-133 \\
\text { tiga la arrogancia c }\end{array}$ & $\begin{array}{l}\text { vv. } \\
\text { Zeus cas- }\end{array}$ & \\
\hline
\end{tabular}




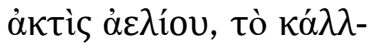

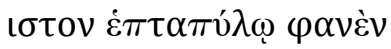

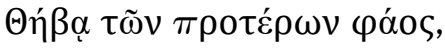

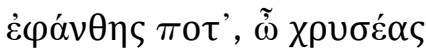

$\dot{\alpha} \mu \varepsilon \dot{\varepsilon} \alpha \varsigma \beta \lambda \dot{\varepsilon} \varphi \alpha \rho o v, \Delta \iota \rho \kappa \alpha i ́-$

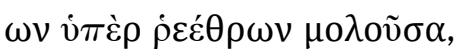

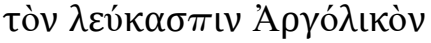

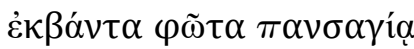

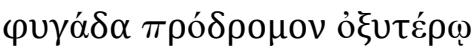

$\kappa เ v \eta ́ \sigma \alpha \sigma \alpha \chi \alpha \lambda \iota v \tilde{\varphi}^{.}$

Rayo de sol, la más hermosa luz vista jamás en Tebas de siete puertas, saliste al fin, oh dorado ojo del día. Viniendo sobre las corrientes dirceas al hombre de Argos de blanco escudo en marcha con armadura completa lo pusiste en fuga veloz con agudísimo freno.

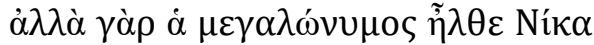

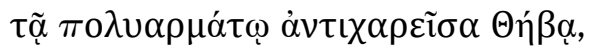
$\dot{\varepsilon} \kappa \mu \dot{\varepsilon} \nu \delta \grave{\eta} \pi \mathrm{o} \lambda \varepsilon \dot{\varepsilon} \mu \omega \nu$

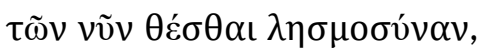

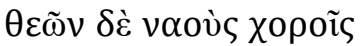

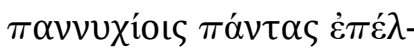
$\theta \omega \mu \varepsilon v, \dot{o} \Theta \hat{\beta} \beta \alpha \varsigma \delta$ ' $\dot{\varepsilon} \lambda \varepsilon \lambda \dot{i}-$

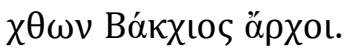

\begin{abstract}
Mas la Victoria, de gran nombre, llegó a Tebas la de muchos carros, devolviendo la alegría, para instituir el olvido de las guerras de ahora. A todas las naves de los templos de los dioses vayamos con coros nocturnos, que Baco que sacude la tierra nos conduzca danzando a Tebas.
\end{abstract}

A y A' presentan himnos a los dioses que llevaron el triunfo a Tebas; en el primer caso, Helios, en el segundo, Nike. Como es común a este género, primero encon-

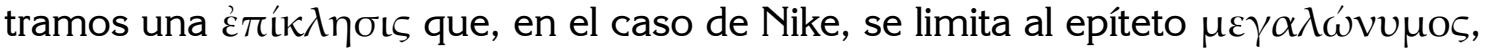
pero en el de Helios admite tres apóstrofes que permiten hacer algunas aprecia-

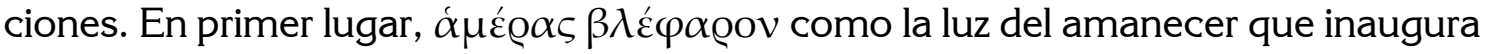
y testifica la jornada trágica. Luego, a través de la aliteración y figura etimológica de

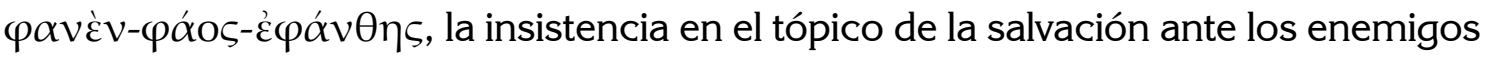
de la ciudad. Como bien señala GRIFFITH (1999: 144), "the light of day is often taken as a symbol of salvation from the darkness of danger or misery". La forma dórica dé $\lambda_{\text {to }}$ y un fraseo similar conectan este comienzo con el del peán 9 de Píndaro (fr. $52 \mathrm{k}$ MAEHLER $)^{27}$, donde el poeta canta ante una audiencia tebana para neutralizar el peligro de un eclipse solar. La conexión entre la luz y, en este caso, la supervivencia,

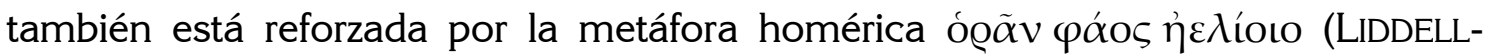
SCOTT-JONES: $I l .7 .421$, etc. "to be alive"), y por qué no pensar en la luz mística que en los misterios representaba un triunfo sobre la oscuridad de la muerte ${ }^{28}$. Las

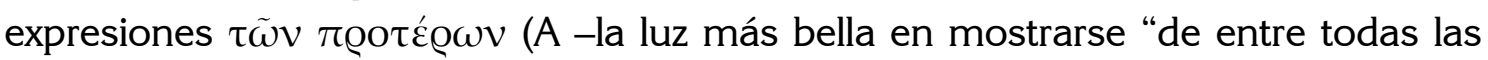
que salieron jamás"-) y $\dot{\alpha} \nu \tau \iota \chi \alpha \varrho \varepsilon \tilde{\tau} \sigma \alpha\left(A^{\prime}\right)$ marcan la reciprocidad de adoración y favor entre la comunidad tebana y los dioses ${ }^{29}$, y explican la transgresión de la

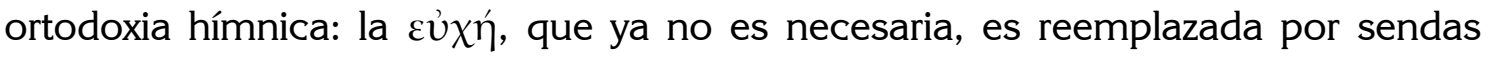




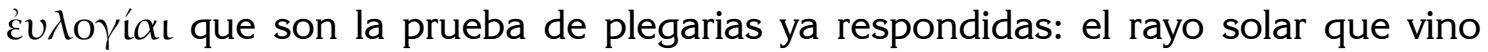
( $\mu \mathrm{o} \lambda \sigma \tilde{v} \sigma \alpha)$ a expulsar ( $\varphi v \gamma \alpha ́ \delta \alpha \kappa \iota v \eta ́ \sigma \alpha \sigma \alpha)$ a los enemigos y la Victoria, que vino $(\tilde{\eta} \lambda \theta \varepsilon)$ a imponer el olvido $(\theta \dot{\varepsilon} \sigma \theta \alpha \iota \lambda \eta \sigma \mu o \sigma v ́ v \alpha v)$ de la guerra reciente. Por otro lado, son evidentes algunos paralelismos sinónimos que insisten en el poder defen-

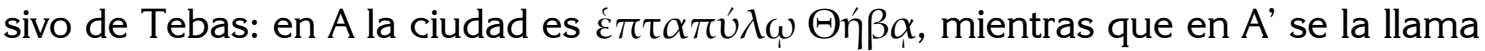
$\tau о \lambda v \alpha \varrho \mu \alpha ́ \tau \omega \Theta \eta ́ \beta \alpha$, eco que es enfatizado por el hecho de que el rayo de luz de $A$

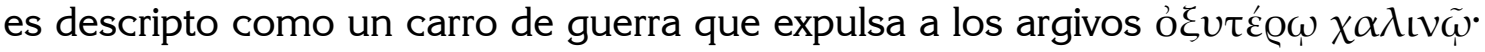
("con agudo freno"). La imagen de la luz como arma tebana se refuerza aún más si

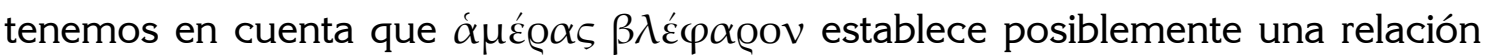
intertextual con la escena de los escudos en Siete contra Tebas, donde la écfrasis del escudo de Tideo describe en él una luna, "ojo de la noche" (v. 390)30. A abunda

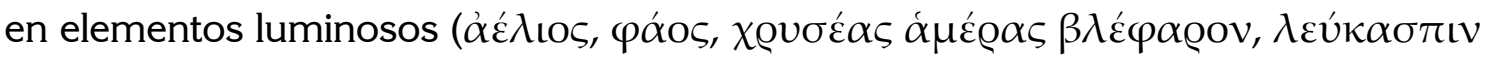

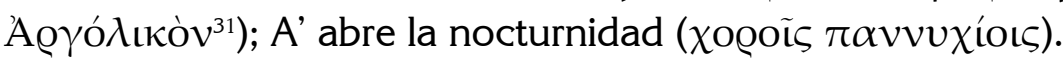

Sin embargo, el contraste entre fijeza y movilidad en A y A' nos permite hacer un primer reparo a estas oposiciones aparentemente consecuentes. En A puede advertirse un movimiento desde Tebas, con énfasis en su fijeza. Como lo muestra el

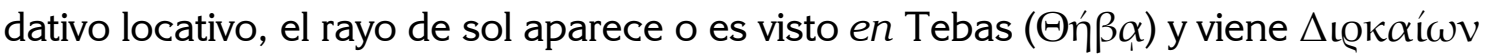

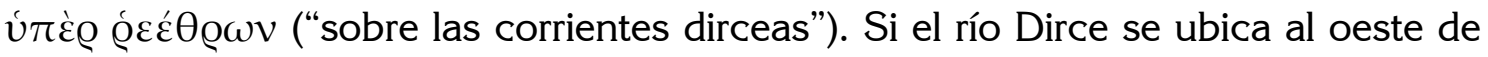
Tebas, y el sol, que llega por el este, ciega y expulsa a los enemigos, entonces estos lo vieron como una divinidad alzándose desde la ciudad, casi como si se tratara de un patrón. La última sección de A', en cambio, presenta un movimiento de los fieles

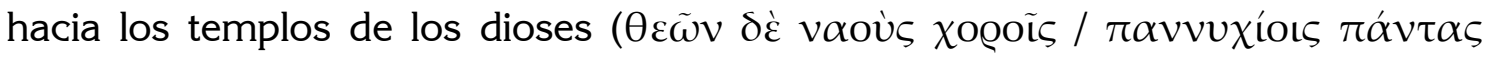
$\varepsilon \dot{\tau} \pi \dot{\lambda} \lambda-$ / $\theta \omega \mu \varepsilon v$ "A todas las naves de los templos de los dioses vayamos con coros nocturnos".) y lo que, en el rito mistérico dionisíaco, sería una procesión báquica hacia la casa real tebana, que implica no ya expulsión de enemigos sino la impulsión de un extraño, que puede ser bienvenido o no. Sin embargo, el pasaje presenta

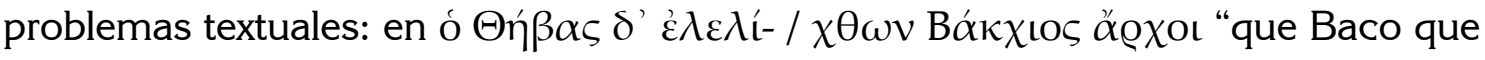
sacude la tierra nos conduzca danzando a Tebas", $\Theta \eta \dot{\eta} \beta \alpha \varsigma$ puede ser interpretado como acusativo plural de $\Theta \tilde{\eta} \beta \alpha \iota$ o como genitivo singular de $\Theta \eta ́ n \beta$, denominación homérica de la ciudad. La enmienda menos aceptada del participio $\dot{\varepsilon} \lambda \varepsilon \lambda i \zeta \omega v$ con acusativo cerraría la cuestión con un objeto directo, pero la enmienda del adjetivo $\dot{\varepsilon} \lambda \varepsilon \lambda \hat{\chi} \chi \theta \omega \nu$ plantea la ambigüedad entre "que sacude la tierra $(-\chi \theta \omega v)$ de Tebas" o

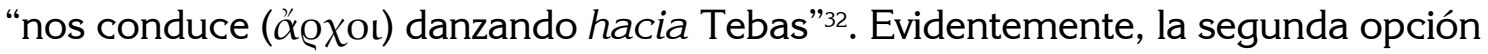
abonaría nuestra interpretación, pero en todo caso, la ambigüedad casual resalta la ironía de esta, si no plegaria, al menos expresión de deseo de la presentación de Baco como dios que guía los coros, y que probablemente sacude la tierra para derrumbar alguna estructura. Ahora, las contradicciones son claras: si bien el rayo de sol es un carro de guerra y constituye el emblema del escudo tebano que se opone al ojo nocturno de Tideo en el enfrentamiento simétrico en las puertas, los enemigos también brillan (v. 107). A esto se suma, como interpreta GRIFFITH (1999:144) cierta vaguedad en la expresión del tiempo: la luz oscila entre 1) la del amanecer sincrónico al canto, 2) la que cegó e hizo huir a los argivos, 3) la que atestiguó la batalla. Ahora, si la luz atestiguó una victoria tebana, ¿̇por qué Nike debería imponer el olvido 


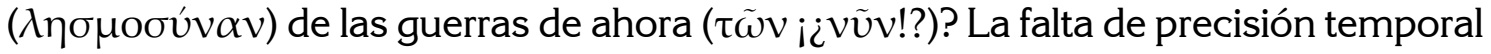
instala la pregunta de si efectivamente se trata de otro día o si se continúa en la batalla de ayer.

Estrofa 2 (B) vv. 110-11

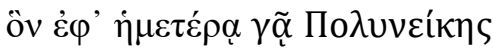

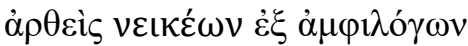

$<\tilde{\eta} \gamma \alpha \gamma \varepsilon \kappa \varepsilon \tilde{\imath} \nu 0 \varsigma \delta^{\prime}$ ỏ $\xi \dot{\varepsilon} \alpha \kappa \lambda \alpha \dot{\zeta} \zeta \omega \nu$

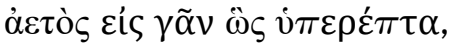

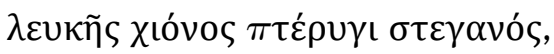

$\pi \mathrm{o} \lambda \lambda \tilde{\omega} \nu \mu \varepsilon \theta^{\prime}$ ö $\pi \lambda \omega \nu$

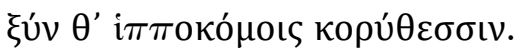

al que, contra nuestra tierra, Polinices

impulsado por polémicas contiendas

llevó. Aquel chillando agudo so-

brevoló la tierra como un águila,

cubierto de alas de blanca nieve, junto

con muchas armas así como con cas-

cos coronados por crines de caballos.
Estrofa 6 (B') vv.141-147

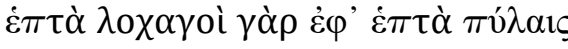

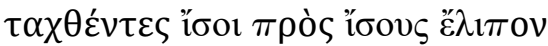

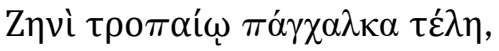

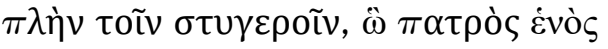

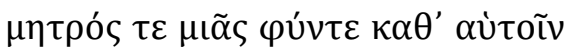

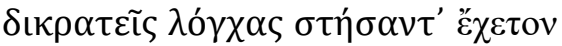

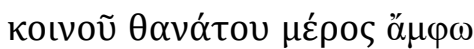

Pues siete jefes sobre siete puertas dispuestos, iguales contra iguales, dejaron como trofeo a Zeus que da la Victoria su final armado de bronce, excepto los dos aborrecidos, de un mismo padre y una misma madre nacidos, después de plantar uno en el otro las lanzas doblemente victoriosas obtienen ambos el lote de la muerte común.

El tema compartido es "amigos y enemigos", pero también podría hablarse de un paralelismo sinónimo entre estas estrofas desde el punto de vista estilístico, ya que su medida en anapestos hace que compartan cierto carácter: quien canta es "the chorus leader (koryphaíos), with the anapests serving to express and supplement the more oblique lyrics rather than to contrast with them" (GRIFFITH 1999: 139). Sin embargo, como veremos, mientras que en B la expresión oscila entre la metáfora y el símil, en B' es simple, sumaria, incluso parca. Si B describe

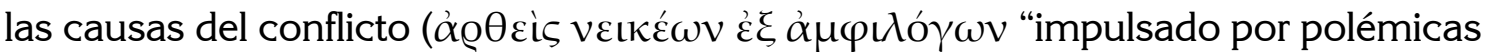

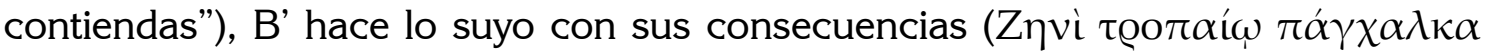

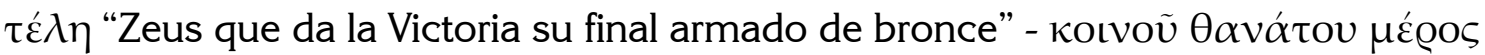
"el lote de la muerte común"), pero cada una presenta al enemigo de modo contrastante. B intenta demarcarlo con claridad: narra que Polinices condujo al extranjero (ôv) "contra nuestra tierra" ( $\dot{\varphi} \varphi$ ' $\left.\eta \mu \varepsilon \tau \varepsilon \dot{Q} \mathcal{Q}_{1} \gamma \tilde{\alpha}\right)$ y lo teratologiza "como un águila"

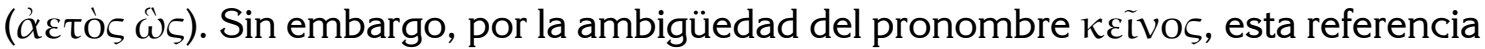
anafórica puede ser válida tanto para él como para el hombre de Argos. Por otra parte, la tensión entre metáfora y símil hace que el ejército argivo sea a la vez Polinices y el águila monstruosa (X es como un águila pero chilla agudo; las alas del 
águila están bien cubiertas por nieve -término sustituyente por el color blanco de las milicias de Argos- y también por cascos y armas, pero no por plumas ${ }^{33}$ ). Esta identificación de Polinices con el enemigo argivo, sin embargo, admite que continúe su identificación con lo brillante propia de la estrofa A (ala cubierta de $\lambda \varepsilon v \kappa \tilde{\eta} \varsigma$ $\chi$ ı́vos), al punto que parece ocupar un lugar parecido al del sol sobre Tebas. En cuanto a B', primero podemos ver un paralelismo sinónimo con B en tanto que se realiza una división amigo-enemigo pero mediada por un fraseo más nítido: una disposición simétrica donde los unos y los otros, si bien distintos, adquieren la

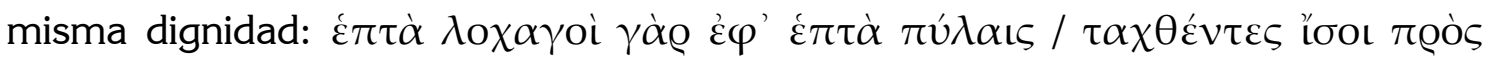
ไбous. ("Pues siete jefes sobre siete puertas dispuestos, iguales contra iguales") Sin embargo, inmediatamente el paralelismo se vuelve antitético; con la misma claridad expresiva, se alude al coito fúnebre del asesinato mutuo entre Eteocles y Polinices:

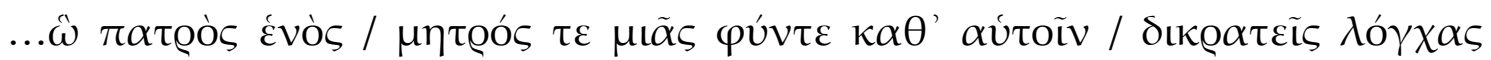

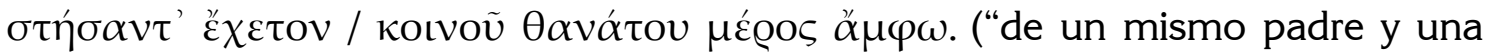
misma madre nacidos, después de plantar uno en el otro las lanzas doblemente victoriosas obtienen ambos el lote de la muerte común") Se trata de una especie de oxímoron, pues identidad y hostilidad se funden. ${ }^{34}$ Podría decirse que en B predomina una pretensión retórica de diferenciar entre amigos y enemigos, traicionada por la ambigüedad del lenguaje usado, mientras que en B' es la claridad meridiana de la expresión la que transmite la indistinción o identificación entre amigos y enemigos. La mención de las armas deja claro el contraste entre la vanagloria de los com-

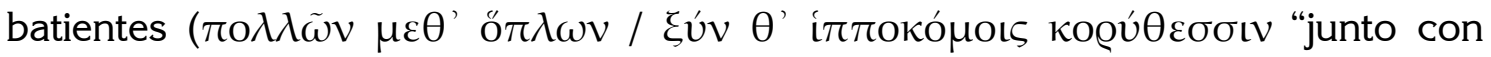
muchas armas así como con cascos coronados por crines de caballos") y la vanidad de la contienda ( $\pi \dot{\alpha} \gamma \chi \alpha \lambda \kappa \alpha \tau \dot{\varepsilon} \lambda \eta^{35}$ "su final armado de bronce").

Estrofa 3 (C) vv. 117-126

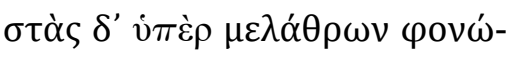

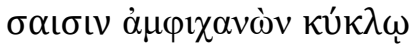

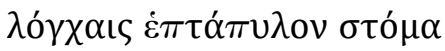

है $\beta \alpha, \pi \rho i ́ v \pi o \theta^{\prime} \dot{\alpha} \mu \varepsilon \tau \varepsilon \dot{\varepsilon} \rho \omega v$

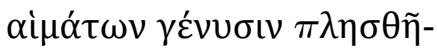

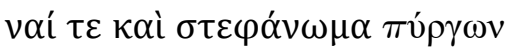

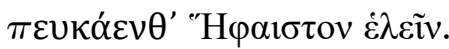

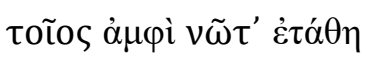

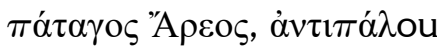

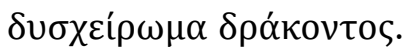

Posado sobre los tejados, cerniendo las fauces, con lanzas en círculo, sedientas de asesinato, sobre la boca de las siete puertas, se retiró antes de
Estrofa 5 (C') vv. 134-140

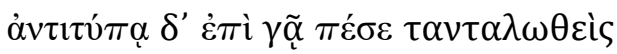

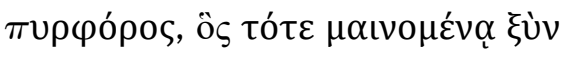

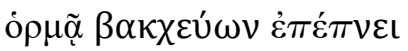

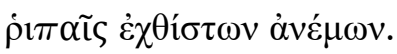

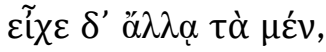

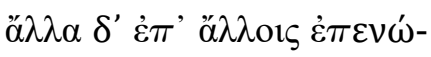

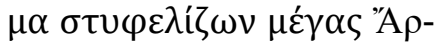

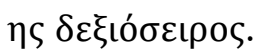

Cayó sobre la tierra firme el portador del fuego habiéndose balanceado como Tántalo, quien con loco impulso, en frenesí báquico, había 
que su pico se llenara de nuestra sangre y el fuego de Hefesto tomara las coronas de las torres, alimentado de pino. Tal entre las espaldas se expandía el clamor de Ares, conquista dura para el rival de la serpiente. soplado con ráfagas del viento más hostil. Las cosas salieron de otra forma, pues otras cosas a otros distribuía, impetuoso, el gran Ares que golpea fuerte.

Ubicados en torno al turning-point (la estrofa D, vv. 127-133), C y C' toman su

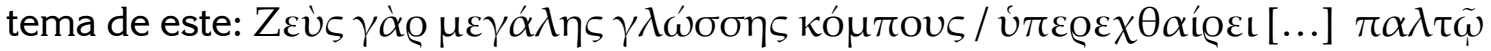

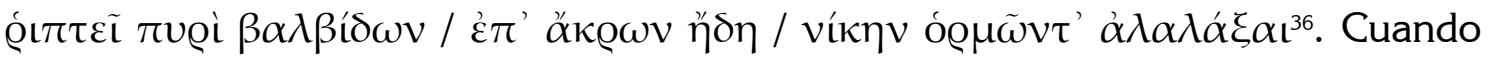
Zeus ve arrogancia, lanza el rayo como castigo. De esta manera ambas estrofas presentan el paradigma mítico de Tántalo (v. 134) como vaivén entre la satisfacción de quien siente haber conquistado un objetivo y la insatisfacción de quien descubre su límite en ese empeñarse ${ }^{37}$. Lo que no queda claro es si Zeus castiga precisamente la desmesura del águila. $C$ comienza poniendo el énfasis en el polo positivo del balanceo tantálico, en el casi logro del objetivo de quien, como un monstruo, estuvo a punto de engullir a Tebas. C', en cambio, comienza por el fracaso (Zeus ya lanzó

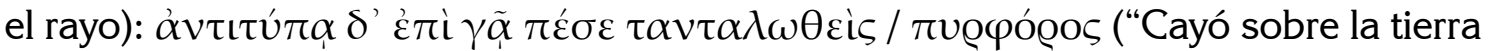
firme el portador del fuego habiéndose balanceado como Tántalo"). Nuevamente

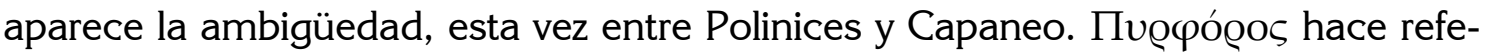
rencia a la antorcha con la que el enemigo se disponía a incendiar las almenas tebanas, y por contraste resignifica en C' el ataque con lanzas sanguinarias ( como lluvia de flechas incendiaras, de modo que sangre y fuego se confunden. Pero

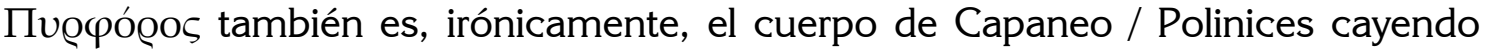
incendiado desde la muralla. El vocabulario báquico ${ }^{38}$ de la estrofa recuerda el nacimiento de Dioniso del rayo de Zeus, tratado etiológicamente en sus misterios así como la importancia de las antorchas en la procesión de su culto en Delfos, e incluso en la procesión de Yaco entre Atenas y Eleusis el diecinueve de Boedromión. Inmediatamente, tanto $C$ como $C$ ' se detienen en la intensidad que la crisis de la batalla hubiese adquirido en caso de continuar (cun guiño hacia los episodios?): en el primer caso, Hefesto se une a la liza con un fuego que se alimenta de madera

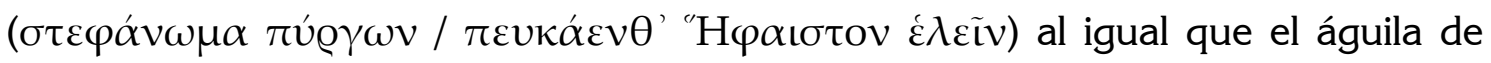

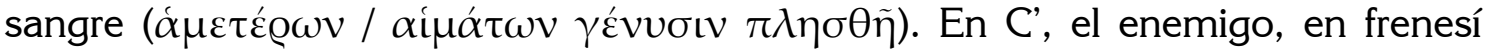

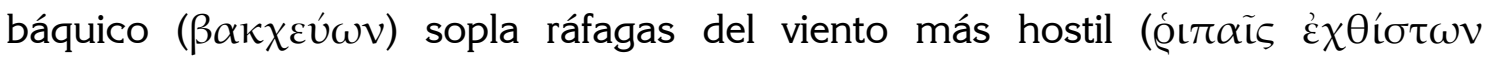

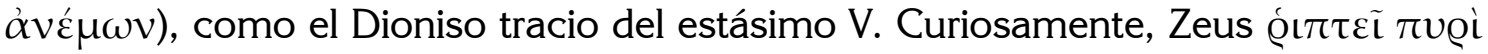
("impulsa el rayo") contra el arrogante en la estrofa central (v. 130), y en la sección final de C', el Ares que se aliaba con el dragón tebano se manifiesta ambiguo en su

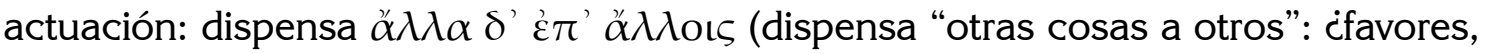

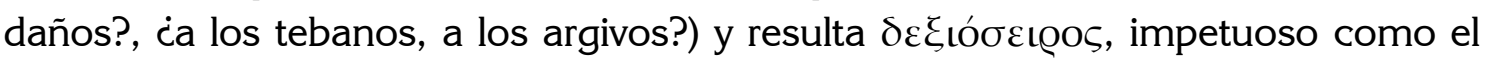
caballo del extremo derecho del carro, pero proclive a desbocarse. Si recordamos que en A el carro era la luz que "salvó" a Tebas, la actuación tanto de Ares como de 
las otras divinidades de la párodos como agentes de la justicia divina, resulta por lo menos borrosa ${ }^{39}$, casi tanto como la identidad de los amigos y los enemigos. Por último la integración caótica de la sangre, el fuego y quizás el vino del éxtasis báquico podría parodiar la visión mistérica de la luz en el Hades (representada en el rito mediante las antorchas en la oscuridad) como símbolo de integración cósmica ${ }^{40}$. Estos elementos se "integran" en la párodos en tanto que se confunden entre sí, esto es, luchan. El rayo y el temblor, que pueden referirse al éxtasis en contextos mistéricos, adquieren aquí un sentido de muerte.

\section{Bibliografía}

\section{Ediciones}

GRIFFITH, M. (1999) Sophocles Antigone, Cambridge.

JEBB, R. C. (2010 [1888]) Sophocles: the plays and fragments, Cambridge.

PADUANO, G. (1982) Tragedie e frammenti di Sofocle. Vols. I-II.

\section{Estudios}

BAJTín, M. (1989 [1936-1937]) "Las formas del tiempo y del cronotopo en la novela. Ensayos sobre poética histórica”. Teoría y estética de la novela, Madrid.

BuSHNELL, R. (2016) Tragic time in drama, film and videogames, London.

BILLINGS, J. (2013) "Choral dialectics: Hölderlin and Hegel". Choral meditations in Greek tragedy (eds. R. Gagné, M. Govers Hopman), Cambridge.

BURKERT, W. (1985) Greek religion, Cambridge, Oxford.

BURKERT, W. (1987) Ancient Mystery Cults, Cambridge - London.

DE JONG, I. (2007) Time in ancient Greek literature, Boston - Leiden.

DE RomiLly, J. (1988) Time in Greek tragedy, New York.

Douglas, M. (2007) Thinking in circles. An essay on ring-composition, New Haven London.

EsPosito, S. (1996) "The changing roles of the Sophoclean chorus". Arion: A Journal of Humanities and the Classics, Third Series, Vol. 4, No. 1, The Chorus in Greek Tragedy and Culture, Two, pp. 85-114.

ESTEBAN SANTOS, A. (1996) "El dos, el tres y el círculo. La forma y el contenido. La obra y la naturaleza", Cuadernos de Filología Clásica. Nro. 6, pp. 37-76.

FRÄNKEL, E. (1955) "Die Zeitauffassung in der archaischen griechischen Literatur", Wege und Formen frühgriechischen Denkes, München, pp. 1-22.

FREIDENBERG, O. ([1956] 2006) Image and concept, mythopoetic roots of literature, Amsterdam.

FURLEY, W. (1995) "Praise and persuasion in Greek hymns", The Journal of Hellenic Studies, Vol. 115, pp. 29-46. 
GARCíA NOVO, E. (1981-82) "Simetría estructural. Importancia de la escena en la tragedia griega”, Habis, Nro. 12, 43-57 y Nro. 13, 17-33.

HEGEL, G. W. F. (1908 [1842]) Estética, Madrid.

---(2000) Rasgos fundamentales de la filosofía del derecho, o compendio de derecho natural y ciencia del estado, Madrid.

Jiménez San CRistóbal, A. (2013) "The Sophoclean Dionysos" en BernabÉ, A; HeRrero de JÁUREGUI, M.; SAN CRISTÓBAL, A. (eds.) Redefining Dionysos, Gotinga.

Kitzinger, R. (2008) The choruses of Sophokles' Antigone and Philoktetes. A dance of words, Boston, Leiden.

LEINIEKS, V. (1996) The city of Dionysos. A study of the Bacchai, Stuttgart, Leipzig.

Lloyd-Jones, H. (1970) Review "Tragic time", The Classical Review, Vol. 20, No. 3, pp. 302-304.

Momigliano, A. (1965) "Time in ancient historiography", History and Theory, Vol. 6, Beiheft 6: History and the Concept of Time, pp.1-23.

MORWOOD, J. (1993) "The double time scheme in Antigone". The Classical Quarterly, Vol. 43, No. 1 , pp. $320-321$

Nussbaum, M. (1986) The fragility of goodness. Luck and ethics in Greek tragedy and philosophy, Cambridge.

PARKER, R. (2000) "Through a Glass Darkly: Sophocles and the divine” en GRIFFIN, J. (ed.) Sophocles Revisited. Essays presented to Sir Hugh Lloyd-Jones, Oxford.

PARKeR, V. (1998) "Túpavvos. The Semantics of a Political Concept from Archilochus to Aristotle", Hermes, 126. Bd., H. 2, pp. 145-172.

RistorTo, M. (2013) "El peán trágico: la párodos de Antígona de Sófocles”, Anales de Filología Clásica. 26, pp. 79-96.

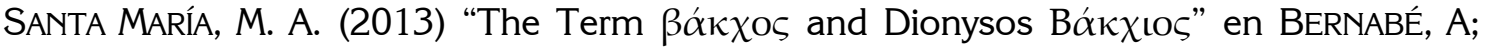
Herrero de JÁUREgUI, M.; SAN CRISTÓBAL, A. (eds.) Redefining Dionysos, Gotinga.

SARAVIA DE GROSSI, M. I. (2007) Sófocles, una interpretación de sus tragedias, La Plata.

---(2011) Antígona. Sófocles. Traducción, notas y estudio preliminar, La Plata.

SCullion, S. (2002) "Nothing to do with Dionysus' Tragedy misconceived as ritual”, The Classical Quarterly, Vol. 52, No. 1, pp. 102-137.

SEAFORD, R. (1981) "Dionysiac drama and the dionysiac mysteries", The Classical Quarterly, Vol. 31, No. 2, pp. 252-275.

---(2010) "Mystic light and near-death experience" en CHRISTOPOULOS, M. (ed.) Light and darkness in ancient Greek myth and religion, New York.

---(2012) Cosmology and the polis. The social construction of space and time in the tragedies of Aeschylus, Cambridge.

SEGAL, CH. (1999) Tragedy and civilization: an interpretation of Sophocles, Cambridge London. 
TORRES, D. (2008) "Respuestas antiguas y contemporáneas ante el anuncio de catástrofes comunitarias: Píndaro, el Peán 9 ante el eclipse de sol y los pronósticos de cambio climático", Revista de Estudios Clásicos, vol. 35, pp. 105-130.

WeIR Smyth, H. (1922) Aeschylus. Vol. 1: Suppliant Maidens, Perseian, Prometheus, Seven Against Thebes. London - Nueva York.

ZeitLin, F. (1985) "Playiyg the Other: Theater, Theatricality, and the Feminine in Greek Drama", Representations, No. 11, pp. 63-94.

---(1986) "Thebes: theatre of Self and Society in Athenian drama" en EUBEN, J. P. (ed.) Greek tragedy and political theory, Los Angeles.

---(1993) "Staging Dionysos between Thebes and Athens". Masks of Dionysos (Eds. Faraone, C.; Carpenter, Th.) Ithaca - London.

\section{Notas}

${ }^{1}$ Para una postura escéptica al respecto, cfr. SCULLION (2002), que resalta la falta de evidencia para demostrar tal aseveración, aunque admite que tampoco existe evidencia para negarla. LEINIEKS (1996: 123-176) incluso especula que la influencia de Bacantes de Eurípides fue el factor determinante, durante el siglo IV, del surgimiento de los misterios. Si bien el propio SEAFORD (1981) acepta que la falta de evidencia impide hacer afirmaciones certeras en torno a la cuestión del origen de la tragedia, considera incuestionable que el género trágico alude a los misterios dionisíacos.

2 "Para la concepción arcaica el tiempo se volvía efectivo en las cosas sucedidas: era la fuerza que todo conducía, en cierto modo el viento que arrastraba los eventos hacia nosotros. Por eso estaba siempre, como Píndaro bien lo dice, viniendo; era tiempo tardío o futuro. Pero en la concepción clásica el tiempo también está con nosotros, los vivientes; está también en nuestros pasos, cuando avanzamos hacia los sucesos y los atravesamos". De aquí en adelante, todas las traducciones corresponden al autor del trabajo.

3 "En los eventos las fuerzas efectivas ya no eran percibidas en las cosas sino introyectadas hacia los vivientes" ([1931]1955: 13).

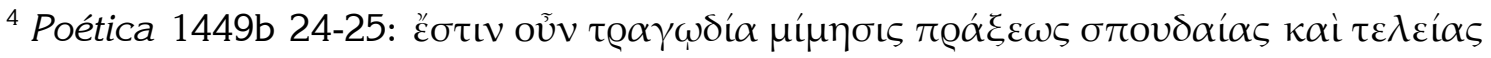
[...]. "Es, pues, tragedia, la mímesis de acciones serias y completas...".

${ }^{5}$ Un día desde el amanecer, para ser precisos. Curiosamente, es en el día (í $\left.\mu \varepsilon_{0} \alpha\right)$ donde FRÄNKEL ve una aproximación homérica a la noción clásica del tiempo ([1931]1955: 5). Se trata de una unidad cerrada y perceptible de experiencia cuyo ritmo se superpone con el de los sucesos e incluso puede actuar activamente ("die Nacht kommt und trennt die Kämpfenden"), pero sobre todo, puede funcionar como marco neutral a sucesos positivos o negativos: "Der Tag ist das Gefäß für das Geschehen, der leere Raum der bereit ist sich mit diesem Inhalt zu füllen".

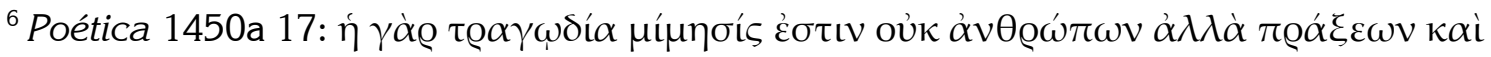
ßíov. "Pues la tragedia no es mímesis de los hombres sino de las acciones y del curso de una vida". 
${ }^{7}$ Viene a cuento recordar la afirmación de Olga FREIDENBERG en relación con el vínculo estrecho entre literatura, culto y mito en la antigüedad: "Greek literature was created without literary precedents, and therefore without literary traditions-in this lies its theoretical importance. It cannot be discussed as one discusses a continuing literature, although the problem is that it is discussed in exactly that way [...] the Classical literary process consisted of the artistic re-creation of images that had not been artistic before" ([1956] 2006: 23). Efectivamente, la tragedia no era un texto escrito para ser leído, sino representado. Y representado en fiestas de sentido cívico y religioso en las que estaba implicada toda la comunidad.

${ }^{8}$ Para una perspectiva narratológica del tiempo en la tragedia, cfr. DE JONG (2007). Para una perspectiva desde la teoría de la acción en mixtura con los estudios de la cultura popular, cfr. BUSHNELL (2016).

${ }^{9}$ Aunque más precisamente en el espíritu de Durkheim, como comenta el mismo SEAFORD (2012: 2), que retoma elementos de la tradición idealista.

${ }^{10}$ Las reformas de Clístenes (508 a. C.), por analogía con el funcionamiento del dinero, aplicaron criterios abstractos y artificiales para definir el cuerpo de ciudadanos. Las diez tribus correspondían a áreas consideradas independientemente de los lazos de sangre entre sus miembros así como de su pertenencia territorial (cada unidad incluía hombres de la costa, del llano y de la ciudad), y así también el calendario urbano, basado en la periodicidad de las pritanías, se alejaba de los criterios naturales del calendario religioso (SEAFORD 2012: 66).

11 "In this way, the crisis of the aetiological myth -what I call the aetiological crisis- is expanded to include the tyrants and resolved, as the aetiological chronotope always was, in the foundation of cult for the whole community" (2012: 113). Recordemos que fue el tirano Pisístrato quien, con dinero, formalizó la performance trágica (107).

${ }^{12}$ Como comprueba Victor PARKER en su interesante artículo (1998), la distinción semántica entre týrannos como monarca que llegó al poder ilegítimamente y basiléus como monarca legítimo es exclusivamente ática y, dentro del dialecto, es absolutamente consecuente en Tucídides y, entre los trágicos, más frecuente solo en Sófocles. Efectivamente Atenas superó la monarquía en pos de otras politeîai en etapas arcaicas de su historia y los reyes están alejados de la memoria colectiva, por lo que esta distinción semántica establece un contraste más bien entre la democracia y la tiranía, viva en la memoria colectiva a través de la experiencia de los Pisistrátidas, e identificada con una acumulación del poder que contradice la isonomía. Pensemos en el Teseo de Edipo en Colono como un basiléus democrático.

${ }^{13}$ Martha NuSSBAum (1986) ve en Antígona un conflicto de la razón práctica a través de dos intentos distintos de eliminar la eventualidad y la tensión de los conflictos en general simplificando la estructura de los compromisos y apegos valorativos y afectivos.

${ }^{14}$ La rhêsis de Creonte (vv. 162-210) abunda en términos anacrónicos, con connotaciones positivas para cualquier ateniense de la pólis democrática: Tódıৎ (vv. 162, 166, 178, 191,

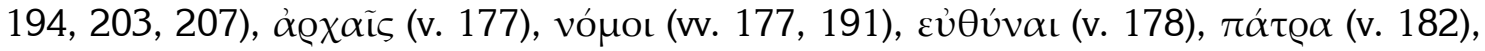
$\chi \theta \omega \dot{v}(187), \gamma \tilde{\eta}$ (v. 199).

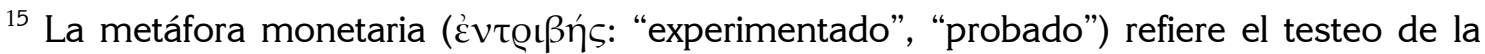
pureza metálica de una moneda, cuyo grado de aleación se comprobaba frotándola contra 
una piedra de toque que la revelaba a través de la coloración de la marca dejada. De ahí su uso figurado para significar "versado".

${ }^{16}$ Para las citas del texto griego seguimos la edición de GRIFFITH (1999)

${ }^{17}$ Como ha demostrado abundantemente ZEITLIN (1985, 1986, 1993), es para hablar de Atenas que la tragedia habla de Tebas, su alter ego didáctico.

${ }^{18}$ Creonte paga el olvido de su lugar como cabeza de un oîkos con una libra de carne (su hijo Hemón), y Antígona intercambia por la unión adelantada con los muertos la pérdida de

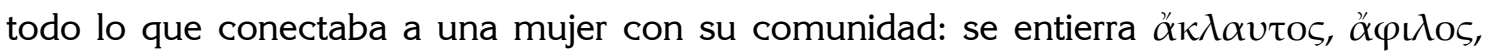

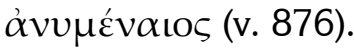

${ }^{19}$ Lo hace al punto tal que abandonará sus campos durante la guerra arquidámica, lo cual lleva a la plaga por hacinamiento de la población (Th. 1, 47.3-54.5).

${ }^{20}$ Cfr. MORWOOD (1933: 320) para un análisis de la impresión de que "Sophocles seems to be working with two clocks."

${ }^{21}$ GARCÍA NOVO (1981), a partir de la simetría entre escenas (marcada por la entrada y salida de personajes) encuentra estructuras anulares perfectamente equilibradas solamente en Edipo en Colono en cuanto a Sófocles, o en Bacantes y Orestes en cuanto a Eurípides, dejando fuera a Esquilo. Admite como un criterio posible de rastreo de la estructura a la comparación de episodios, y cita el trabajo de Aichele (47): Aichele, K. (1971) "Das Epeisodion". Die Bauformen der griechische Tragödie (Ed. W. Jens): Munich. MARÍA INÉS SARAVIA (2012: 84-85), en el estudio preliminar de su traducción de Antígona, realiza un cuadro con la simetría entre episodios, que comenzarían su cuenta regresiva luego del segundo estásimo. Mientras que la primera parte se caracteriza por: a) cierta morosidad, b) la tragedia en miniatura de Ismena, c) los grandes discursos racionales, d) la predominancia de Antígona, d) el agón Antígona/Creonte, e) la presencia de muertos identificados como enemigos, f) la actuación ridícula del mensajero y g) el aspecto aquileo y lógico de Antígona, etc.; la segunda se caracteriza por: a) su agilidad, b) la tragedia en miniatura de Eurídice y de Hemón, c) las consecuencias concretas de poderes irracionales y la falla en el habla, d) la predominancia de Creonte, d) los agones Creonte/Hemón, Creonte/Tiresias, e) la presencia de muertos en la propia familia, f) la actuación sublime del mensajero y g) el kommós patético de Antígona.

${ }^{22}$ Esteban SANTOS (1996: 10) llama la atención sobre las tragedias euripideas donde el tema de la muerte ocupa el eje de la obra y sus extremos: Troyanas, Medea, Heraclidas e Hipólito.

${ }^{23}$ Alceo (6 LPG), Teognis (vv. 670-685), Esquilo (Siete contra Tebas, vv. 107, 192, 780, 1068; Euménides, v. 16).

${ }^{24}$ Cfr. KitZinger (2008: 10-11) y De Romilly (1968: 29 y ss.)

${ }^{25}$ Esto se manifiesta, claro, en la pluralidad de divinidades en los coros. La secuencia de odas corales desarrolla el tema: "man in the grip of dark, sinister, morally ambivalent forces that work unpredictably for his humilliation and destruction" (ESPOSITO 1996: 90).

${ }^{26}$ Los anapestos finales de cada estásimo actúan como indicación escénica que reconecta con la acción. 
${ }^{27}$ Para una lectura de esta sección exclusivamente como peán, cfr. RISTORTO (2013). Para una lectura del eclipse como catástrofe comunitaria y su tratamiento en el peán pindárico, cfr. TORRES (2008).

${ }^{28}$ Para una descripción completa de los lugares textuales de esta luz, cfr. SEAFORD (2010). BURKERT señala a propósito de la pérdida del miedo a morir durante la iluminación mística "the certainty of life gained by intoxication and sexual arousal goes together with insight into the cycle of nature. At the same time the special status attained through initiation is claimed to be valid even beyond death, the orgiastic festival of the mystai continues to be held in the afterlife" (1985 [1977]: 289]. El mismo autor profundiza su reflexión sobre los misterios en una obra posterior (1987).

${ }^{29}$ En palabras de FURLEY (1995: 32): "The relation aimed at between worshipper and deity was one of $\chi \alpha \dot{Q} \varrho ı$, , a word with two complementary senses, like the faces of a coin. As Race has shown, charis denotes both the adoring worship by people of a god, and, conversely, the reciprocal grace or favour with which the people hope a god will reward them in turn".

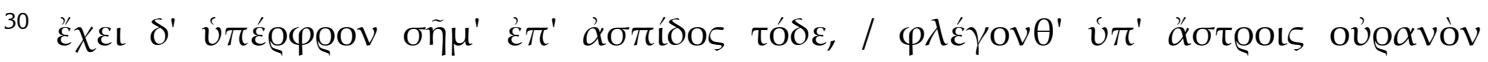

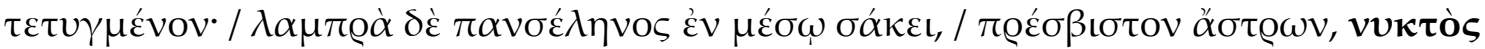

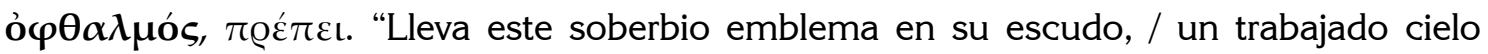
incenciado de estrellas: / en el medio del escudo la brillante luna llena, / el más reverenciado de los astros, ojo de la noche, se destaca" (Esquilo, Siete contra Tebas, vv. 387-390).

${ }^{31}$ Sófocles juega con la falsa etimología de Argos, que estaría relacionada con d’@ ("brillante").

32 PADUANO se guía por la primera opción (1982: 265): "e nostra guida sia Baco, che anima questa terra". Igualmente JEBB (2010 [1888]: 39): "And may Bacchus be our leader, whose dancing shakes the land of Thebes". SARAVIA (2012: 102), en cambio, se inclina por la segunda: "Y ojalá que Baco, que sacude la tierra, nos conduzca a Tebas".

${ }^{33}$ Los campos sustituyente y sustituido del sistema metafórico no se presentan puros ni completos: se atribuye al sustituyente el campo semántico del sustituido y se presenta solamente un componente de la serie metonímica del complejo, volviéndose imposible rastrear cuál de sus metáforas la inauguró.

${ }^{34}$ Cfr. PADUANO (1982: 263): "la límpida simmetria degli schieramento viene alla fine negata dall' intreccio perverso di identità e ostilità".

${ }^{35}$ TÉ $\lambda$ os en este caso significa "muerte".

36 "Pues Zeus odia la jactancia de las lenguas ostentosas en exceso [...] precipita blandiendo el fuego a quien desde las elevadas almenas ya se predisponía a cantar victoria."

${ }^{37}$ El castigo de Tántalo, gran violador de ritos, en el Hades, consistía en estar sumergido en agua hasta el cuello y no poder beberla y tener frutos colgando sobre la cabeza y no poder comerlos.

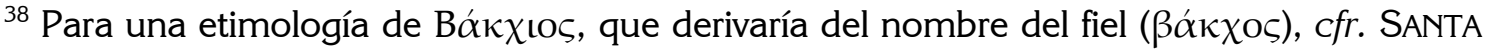
MARÍA (2013). JIMÉNEZ SAN CRISTÓBAL (2013) señala que las únicas obras conservadas de Sófocles donde aparece Baco (y solamente en los coros) son las tragedias tebanas, Traquinias y Áyax. Existen fragmentos trágicos atribuibles a Sófocles que remitirían a tragedias que trataron directamente mitos dionisíacos: Tereo, Atamante, Las coéforas, Erígona, Bacantes, Fineo o los músicos de tambor, o el drama satírico El niño Dioniso. El 
mito eleusino posiblemente fue tratado en Triptólemo. Para los fragmentos sofocleos, ver LuCAS DE Dios, J. M. (trad.) (1983) Sófocles. Fragmentos, Madrid.

${ }^{39}$ Para un interesante análisis de la inescrutabilidad de los dioses sofocleos y la "teodicea negativa" que implica intentar leer su conexión con los destinos humanos, cfr. PARKER (2000).

40 Bacantes 918-924, Ranas 155-156, fragmentos conservados de Basárides, etc. Para profundizar en esta imagen como símbolo de interconexión cósmica, cfr. SEAFORD (2012: 41). 